\title{
Robust and Bright Genetically Encoded Fluorescent Markers for Highlighting Structures and Compartments in Mammalian Cells.
}

\begin{abstract}
Anna O. Chertkova ${ }^{1}$, Marieke Mastop ${ }^{1}$, Marten Postma ${ }^{1}$, Nikki van Bommel ${ }^{1}$, Sanne van der Niet ${ }^{1}$, Kevin L.Batenburg ${ }^{1}$, Linda Joosen ${ }^{1}$, Theodorus W.J. Gadella Jr. ${ }^{1}$, Yasushi Okada ${ }^{2}$, Joachim Goedhartt ${ }^{1}$,

${ }^{1}$ Swammerdam Institute for Life Sciences, Section of Molecular Cytology, van Leeuwenhoek Centre for Advanced Microscopy, University of Amsterdam, P.O. Box 94215, NL-1090 GE Amsterdam, The Netherlands

${ }^{2}$ Laboratory for Cell Polarity Regulation, Quantitative Biology Center (QBiC), RIKEN, Osaka, Japan \& Department of Physics and Universal Biology Institute, Graduate School of Science, the University of Tokyo, Tokyo, Japan
\end{abstract}

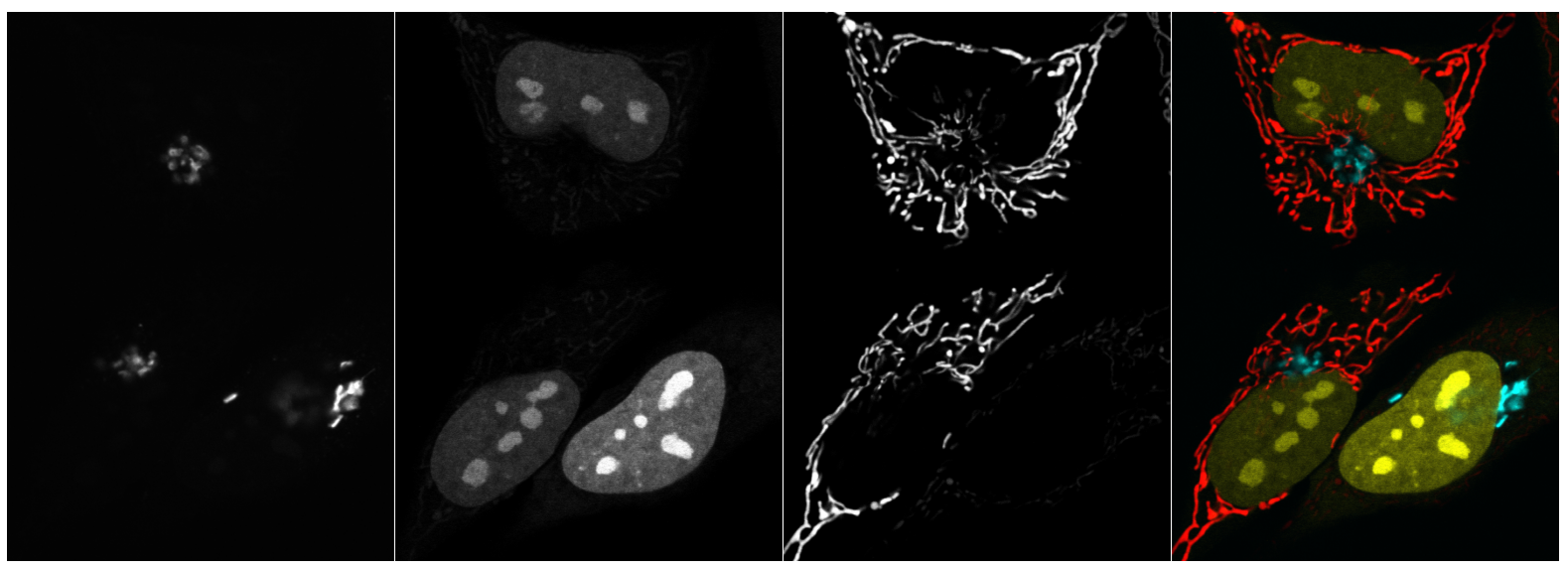

\section{Abstract}

To increase our understanding of cells, there is a need for specific markers to identify biomolecules, cellular structures and compartments. One type of markers comprises genetically encoded fluorescent probes that are linked with protein domains, peptides and/or signal sequences. These markers are encoded on a plasmid and they allow straightforward, convenient labeling of cultured mammalian cells by introducing the plasmid into the cells. Ideally, the fluorescent marker combines favorable spectroscopic properties (brightness, photostability) with specific labeling of the structure or compartment of interest. Here, we report on our ongoing efforts to generate robust and bright genetically encoded fluorescent markers for highlighting structures and compartments in living cells.

\footnotetext{
\# corresponding author: j.goedhart@uva.nl, @joachimgoedhart
} 


\section{Introduction}

It is difficult to overestimate the impact that Green Fluorescent Protein had and has on basic and applied research. The isolation of the CDNA encoding GFP from the jellyfish Aequorea victoria (Prasher et al., 1992) has enabled scientists to track molecules, organelles, protein complexes or cells at different time (milliseconds to days) and length scales (nanometer to centimeter). Fluorescent proteins (FPs) with different emission colors that have since been generated or isolated from different sea-resident animals can be used to highlight independent events simultaneously (Shaner et al., 2005).

By attaching the CDNA encoding a FP to the CDNA of a peptide or protein of interest, specific labeling is achieved. One particular application in cell biology is to use FP fusions as fluorescent markers that highlight structures and compartments in cells. These structures can be visualized with fluorescence microscopy. By employing markers with different emission colors (Rizzuto et al., 1996), the relative location of several structures can be studied (e.g. location of ER relative to mitochondria). Another application of markers is to identify the residency of a biomolecule with an uncharacterized location.

Regardless of the application, it is crucial to use markers that show specific, crisp labeling, without spurious, non-specific localization. In addition, it is practical to have a palette of bright fluorescent markers, to facilitate coimaging. Here, we report on our ongoing efforts to generate robust and bright genetically encoded fluorescent markers for highlighting structures and compartments in living cells.

\section{Results}

Previously, we have published a number of markers that highlight a variety of structures and compartments (Bindels et al., 2017; Goedhart et al., 2012). However, we noted that some of these markers also showed spurious localization of the fluorescent protein, i.e. unrelated to the compartment of interest. Below we describe the results of (i) improvements of exisiting markers and (ii) construction of new combinations of existing markers with established bright fluorescent proteins.

Our choice of FPs is based on (i) high cellular brightness in a spectral class, (ii) good photostability and (iii) monomeric behavior in cells. Based on these criteria, we use the FPs mTurquoise2 (cyan), mNeonGreen (green) and mScarlet-I (red). In the future, this palette of fluorescent proteins may be complemented with other variants, including large Stokes-shift FPs (Shcherbakova et al., 2012) or IR emitting proteins (Shcherbakova et al., 2016) to allow for an even broader range of options. 


\section{Mitochondria}

We observed that the mitochondrial marker, comprising mTurquoise 2 and a signal peptide from COX8A (Goedhart et al., 2012), showed substantial cytoplasmic labeling. To increase mitochondrial targeting we replaced the single sequence by a 4 times repeated mitochondrial target sequence (mts) derived from $4 \mathrm{mtD} 3 \mathrm{cpv}$. Co-expression of the $1 \mathrm{xmts}$ and $4 \mathrm{xmts}$ variant show a crisp labeling of the mitochondria for the $4 x m t s$ variant, with hardly any cytoplasmic fluorescence (Figure 1).
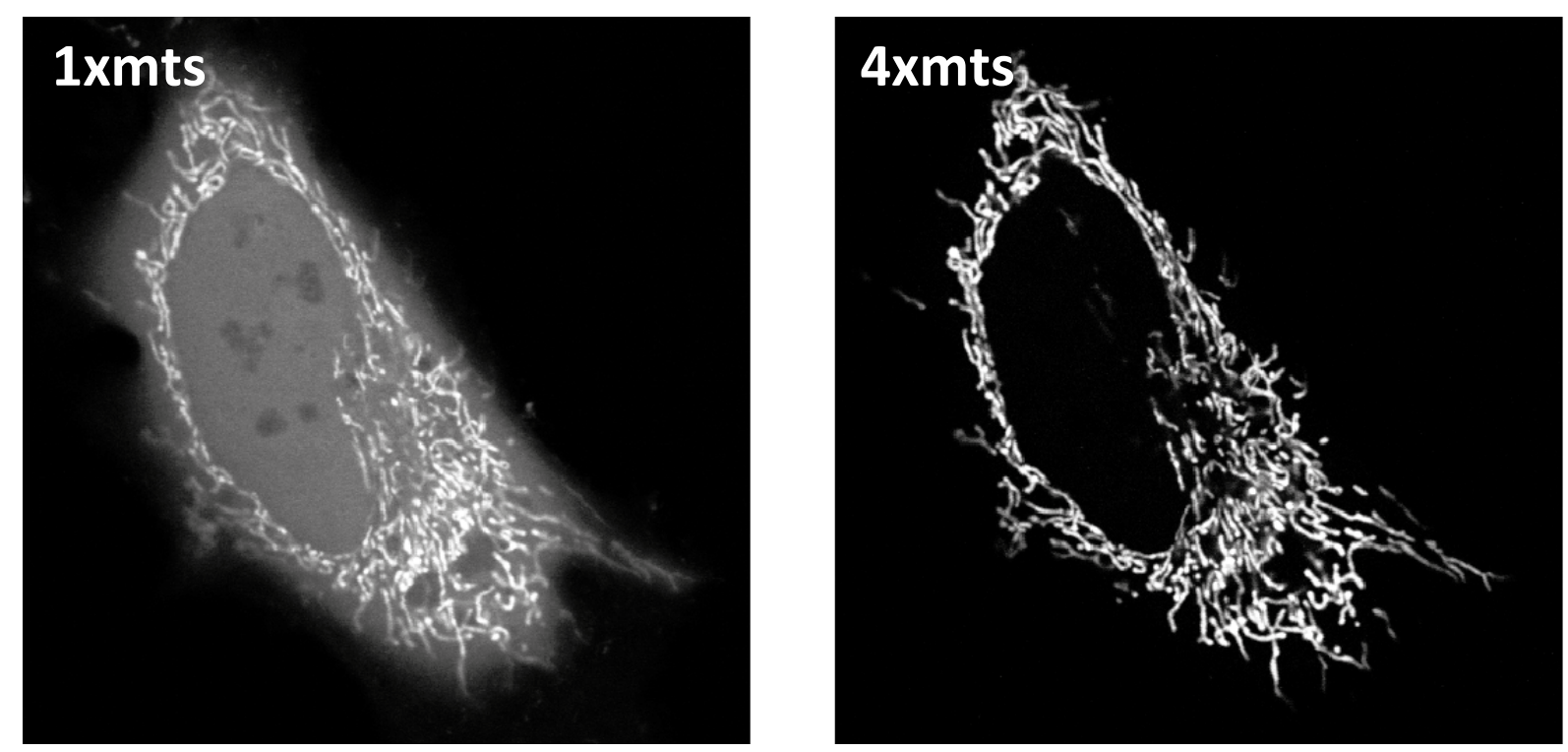

Figure 1: HeLa cell co-transfected with the plasmids encoding a fluorescent protein tagged with $1 \times x m t s$ and $4 x m t s$ to label mitochondria. The width of the images is $71 \mu \mathrm{m}$.

(Left: 1xmts-mTurquose2, right: 4xmts-mScarletl)

\section{Nucleus}

To target proteins to the nucleus, a strong nuclear localization signal (nls) is usually attached to the protein of interest. As fluorescent proteins are small enough to move out of the nucleus through the nuclear pores, substantial cytoplasmic fluorescence is observed for nls-mTurquoise. To improve nuclear localization, a triple nls, 3xnls (Joosen et al., 2014), sequence was employed. The variant with $3 x n l s$ shows increased nuclear labeling relative to cytoplasmic labeling when compared to a fluorescent protein with 1xnls (Figure 2). We also noted that the $3 x n l s$ variant shows enhanced labeling of nucleoli. 

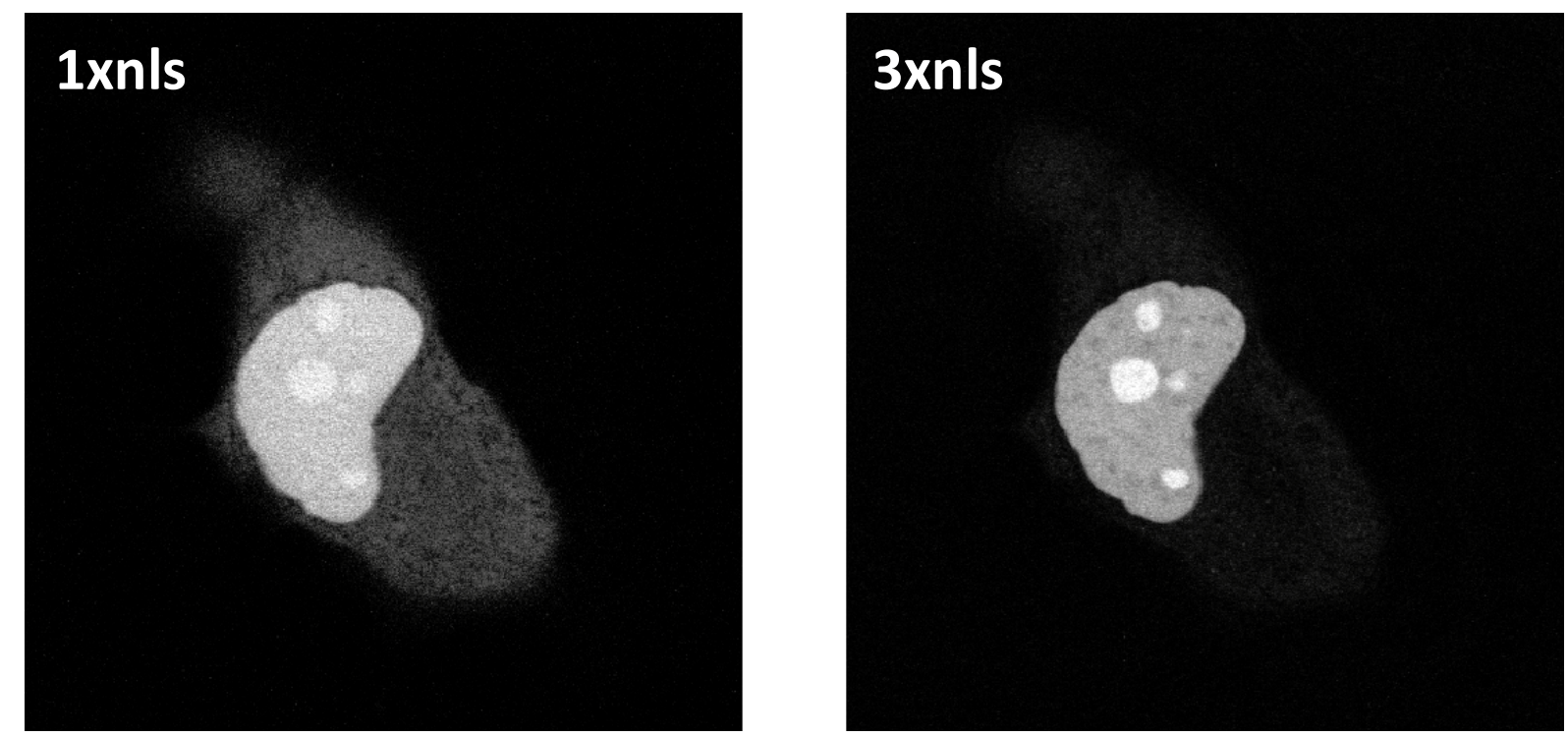

Figure 2: HeLa cell co-transfected with the plasmids encoding a fluorescent protein tagged with $1 \times x n l s$ and $3 x n l s$ to highlight the nucleus. The width of the images is $71 \mu \mathrm{m}$. (Left: 1xnls-mTurquoise2, right: 3xnls-mScarletl).
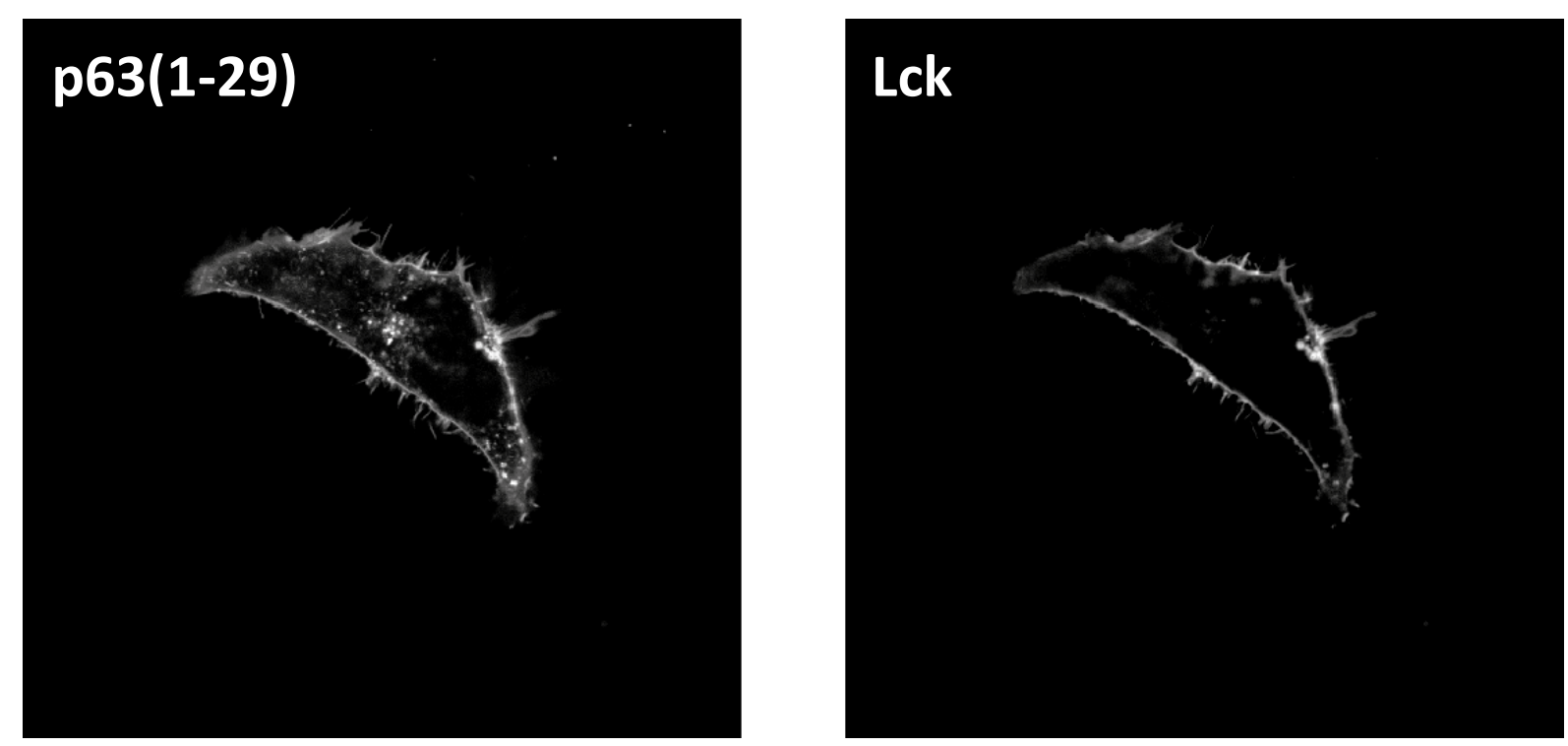

Figure 3: HeLa cell co-transfected with the plasmids encoding a fluorescent protein tagged with the plasma membrane targetin sequence derived from p63(1-29) and Lck. The width of the images is $108 \mu \mathrm{m}$.

(Left: p63(1-29)-mTurquoise2, right: Lck-mScarletl).

\section{Plasma membrane}

The cysteine-rich sequence of p63RhoGEF was previously used to highlight the plasma membrane (Goedhart et al., 2012). In addition to plasma membrane located fluorescence, we noticed numerous intracellular puncta (figure 3, left panel). To create a marker for the plasma membrane with improved selectivity, we explored different peptides. Among the different sequences tested (derived from Lck, Gap43, Src, KRas), we observed the most efficient membrane labeling for the motif from Lck, with hardly any labeling of 
endomembranes (figure 3). Therefore, we recommend to use the Lck-tagged fluorescent proteins as a robust marker for the plasma membrane.

Golgi apparatus

Initially, we used a sequence derived from GalT to make a Golgi marker (Goedhart et al., 2012). To evaluate whether this is the optimal marker for Golgi labeling we co-expressed this variant with fluorescent proteins tagged with sequences of Golgi resident proteins, i.e. Giantin (Komatsu et al., 2010) and Sialyltransferase. When introduced into HeLa cells, the fusions with giantin showed labeling that is confined to the Golgi apparatus, whereas the GalT marker showed labeling of punctuate structures, in addition to labeling of the Golgi apparatus (figure 4). Therefore, the giantin fusion is the marker of choice for the Golgi apparatus.
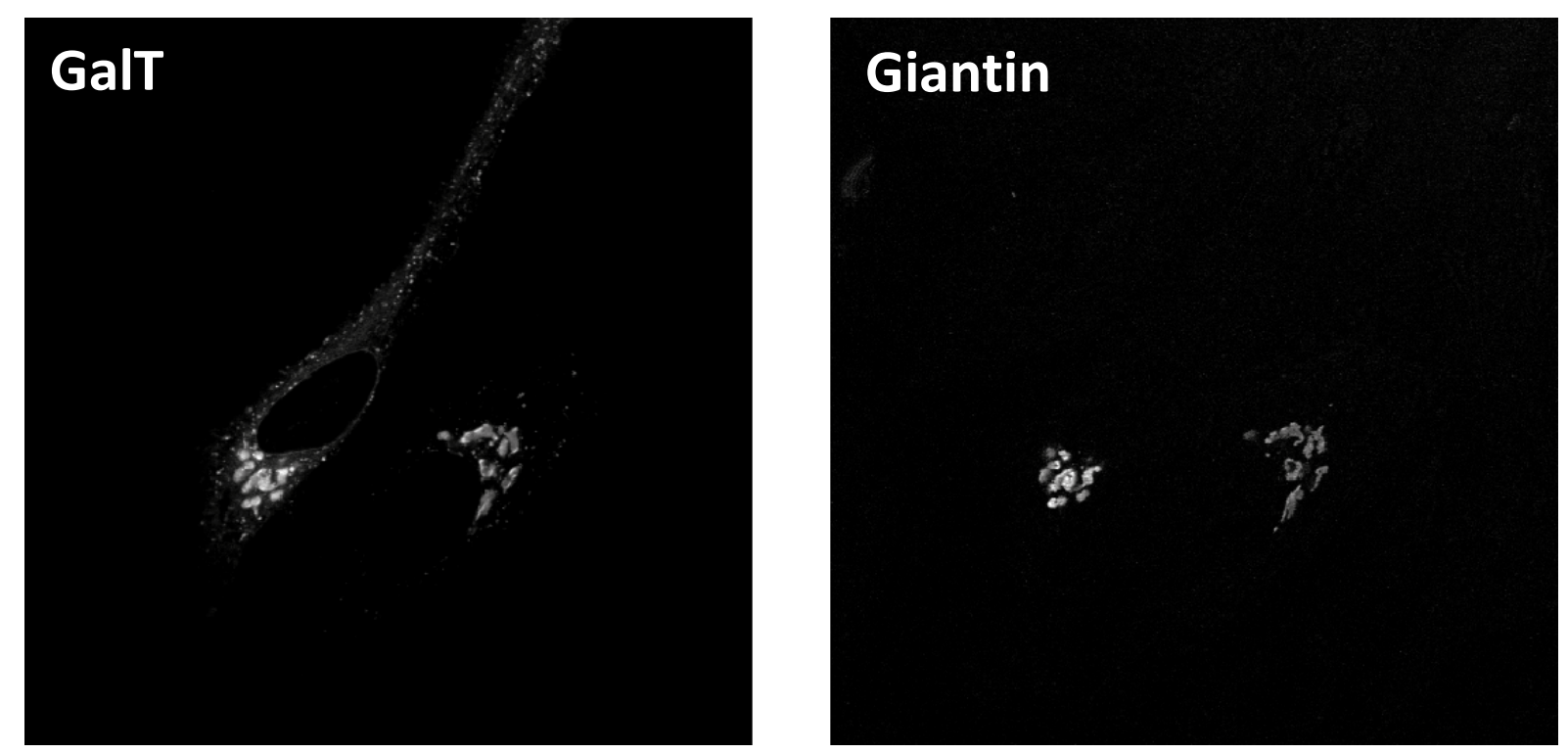

Figure 4: HeLa cell co-transfected with the plasmids encoding a fluorescent protein tagged with GalT and Giantin to mark the Golgi apparatus. The width of the images is $143 \mu \mathrm{m}$. (Left: GalT(1-61)-mTurquoise2, right: mScarletl-Giantin(3131-3259)).

\section{Lysosomes}

Thus far, no lysosomal marker fused with either mTurquoise2 or mScarlet-I was available. To construct a lysosomal marker we used the lysosomal associated membrane protein 1 (LAMP1). This fusion protein is expected to decorate lysosomes and indeed, we observed labeling of punctuate structures (figure 5) 


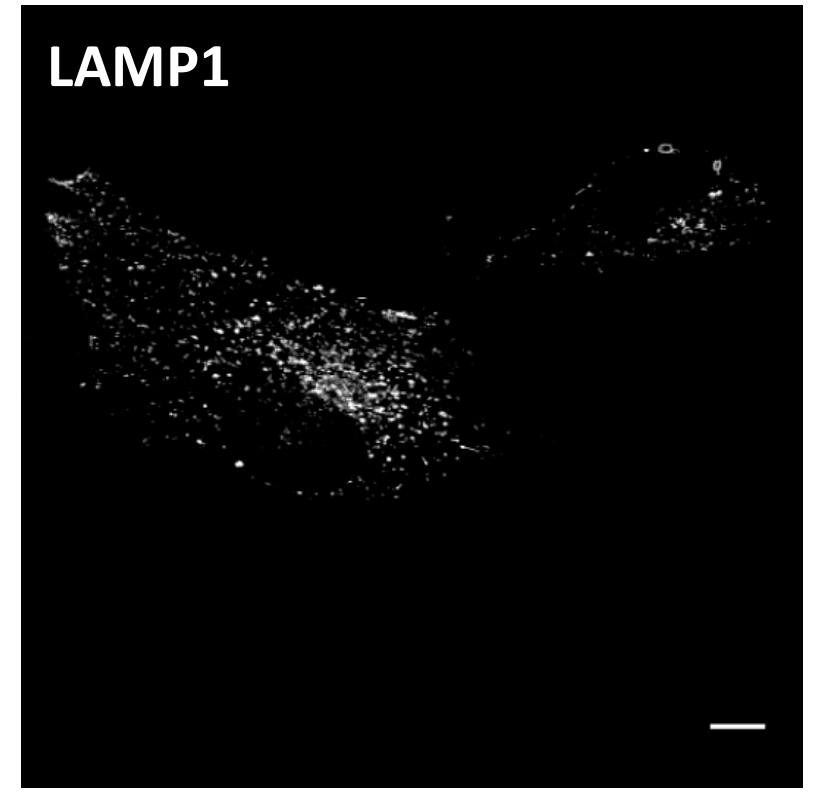

Figure 5: HeLa cell transfected with a plasmid encoding a fluorescent protein tagged with LAMP1 to mark the lysosomes. The width of the images is $143 \mu \mathrm{m}$.

(mScarletl-LAMP1)

\section{Actin cytoskeleton}

The actin cytoskeleton can be labeled by tagging actin itself with GFP. However, this results in labeling both the soluble, monomeric G-actin pool and the polymerized, filamentous actin (F-actin) pool. To study the cytoskeleton, it is often desired to selectively label actin filaments. To this end, peptide sequences or protein domains have been identified that preferentially bind Factin, such as lifeact (Riedl et al., 2008), Utrophin-CH (Burkel et al., 2007) and ITPKA(9-52)/F-tractin (Johnson and Schell, 2009). Previously, we have described lifeact fusions with mTurquoise2 (Goedhart et al., 2012) or mScarlet (Bindels et al., 2017). To allow for a wider choice of markers, we made combinations of the bright fluorescent proteins mTurquoise2, mNeonGreen and mScarlet-I with the actin probes Lifeact, Utrophin-CH and ITPKA (residue 940). Note that we used a shorter version of Ftractin here (the original Ftractin probes corresponds with residue 9-52 from rat ITPKA, while here we use residue 9-40), without any noticeable difference. All three fusion constructs show pronounced labeling of the actin cytoskeleton (figure 6). It is of note that different markers may label different $\mathrm{F}$-actin pools and may have different properties (Belin et al., 2014; Ganguly et al., 2015; Spracklen et al., 2014). Therefore, validation in the system of choice is warranted and the choice of the marker depends on the application. 

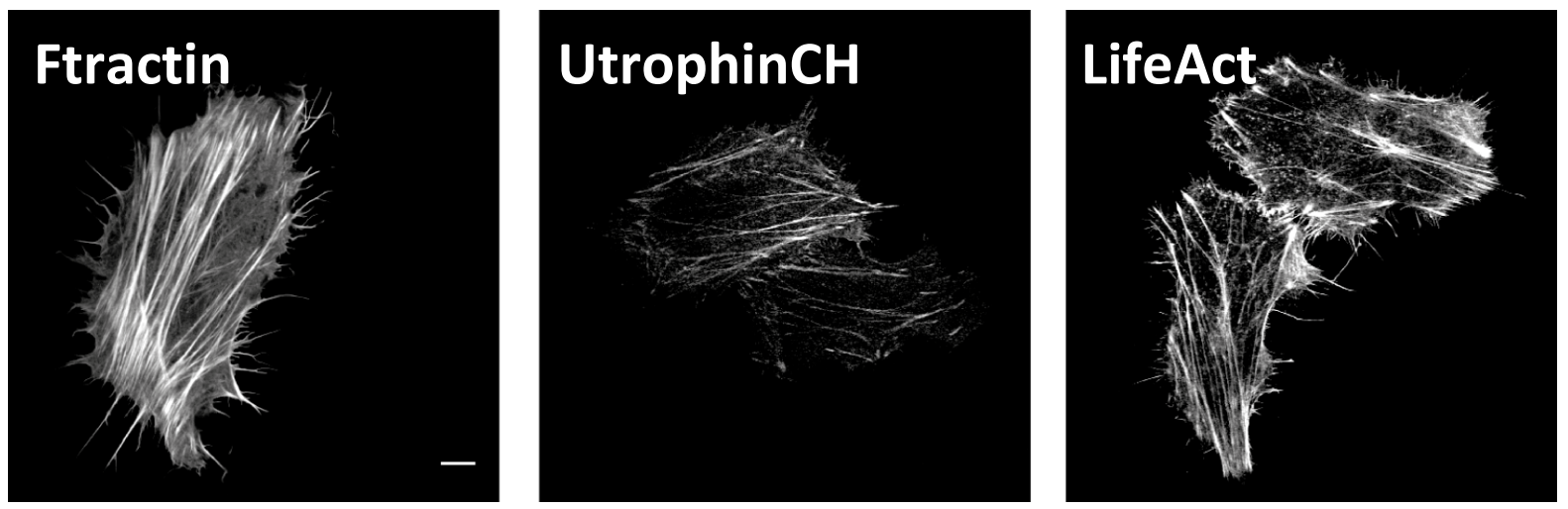

Figure 6: HeLa cell transfected with a plasmid encoding a fluorescent protein tagged with ITPKA or UtrophinCH or Lifeact to visualize the F-actin cytoskeleton. The width of the images from left to right is $116 \mu \mathrm{m}, 143 \mu \mathrm{m}$ and $143 \mu \mathrm{m}$.

(From left to right: ITPKA(9-40)-mTurquoise2, mNeonGreen-UtrCH, Lifeact-mScarletl).

\section{Microtubules}

To label the microtubules, FPs can be fused either to the N-terminus of alphatubulin (Bindels et al., 2017; Goedhart et al., 2012) or to the C-terminus of beta-tubulin. The protein level of fusion tubulin should be carefully controlled for optimal results. Too much expression leads to higher cytoplasmic signals from unpolymerized tubulin, and also affects the microtubule dynamics. Detailed analyses on the effects by tubulin fusion protein expression are reported with fission yeast (Snaith et al., 2010).

The microtubule binding domain of microtubule associated proteins (MAPs) such as EMTB can also used as marker for microtubules, but these have a tendency to facilitate stabilization and bundling of microtubules.

Another class of microtubule binding proteins, +-TIPs that bind preferentially to the growing plus-ends of the microtubules can be used as the marker for microtubule growth (Stepanova et al., 2003). Among them, EB1 or EB3 fused with an FP is widely used. We observed "comet"-like staining of the growing ends of microtubules with both EB1 (not shown) and EB3 based fusion constructs of mTurquoise2 (Figure 7), mNeonGreen, and mScarlet-I. Their brightness and the photostability along with the rapid exchange of the bound populations with the cytoplasmic pool enabled live imaging of microtubule growth at sufficiently low expression levels. A low concentration of the marker is essential for correct measurement of the microtubule dynamics. Higher expression levels can cause hyperstabilization of the microtubules, lower contrast to the background signals from the cytoplasmic pool. At even higher expression levels, their signals extend from the tips to the body of the microtubules. 
bioRxiv preprint doi: https://doi.org/10.1101/160374; this version posted July 6, 2017. The copyright holder for this preprint (which was not certified by peer review) is the author/funder, who has granted bioRxiv a license to display the preprint in perpetuity. It is made available under aCC-BY-NC-ND 4.0 International license.

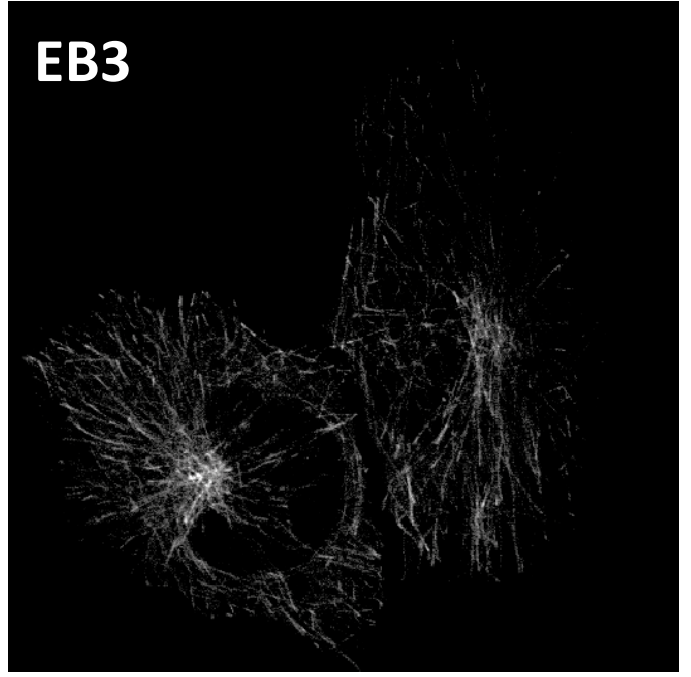

Figure 7: HeLa cell transfected with a plasmid encoding a fluorescent protein tagged with EB3 to detect the growing tips of microtubuli (EB3-mTurquoise2). The width of the image is $86 \mu \mathrm{m}$. 


\section{Conclusion}

Fluorescent markers are essential components of the cell biologist's toolkit. Several of the previously reported markers show non-specific, suboptimal labeling of structures or compartments. Here, we report markers with improved labeling of the structure or compartment of interest with reduced non-specifc labeling. In addition, we have generated new combinations of markers with the brightest monomeric fluorescent proteins currently available. Our analysis of the labeling patterns and improvements is limited to observations after transient transfection in HeLa cells. It is highly recommended that independent verification of the labeling quality is performed. This is of particular importance, if the markers are intended for different cell lines or organisms.

To conclude, we anticipate that the improved markers will be valuable for future live cell imaging studies. 


\section{Materials and Methods}

\section{Plasmids}

The bright monomeric fluorescent proteins used in this study, mTurquoise2 (Goedhart et al., 2012), mNeonGreen (Shaner et al., 2013) and mScarlet-I (Bindels et al., 2017) have been described previously. Plasmids with Lck (van Unen et al., 2016) and Giantin (Bindels et al., 2017; van Unen et al., 2015) have been described before.

Plasmids with mCherry-LaminB (Bas van Steensel), EB3-EGFP-N1 (Niels Galjart) EGFP-LAMP1 (Eric Reits) were kind gifts.

Plasmids with pcDNA-4mtD3cpv (addgene Plasmid \#36324), GFP-UtrCH (addgene plasmid \#26737), 3xnls (addgene plasmid \#60492) were from www.addgene.org

In many cases, existing plasmids were used to generate new combinations by exchanging the fluorescent protein in the clontech-style plasmid that encodes the marker (usually using the restriction enzymes Agel/BsrGl), with the following exceptions:

The $4 \mathrm{mts}$-mTurquoise 2 is made by a partial digest of pcDNA-4mtD3cpv (Addgene Plasmid \#36324) with HindIII and the insert is ligated in mTurquoise2 cut with HindIII.

The Utrophin $\mathrm{CH}$ domain is excised from the plasmid GFP-UtrCH (addgene plasmid \#26737) with BsrGl and Sacl and ligated in mTurquoise2-C1 cut with BsrGI and Sacl.

LAMP1-mTurquoise2 was generated by a PCR on LAMP1-GFP (primer sequences: forward, 5'-AGCGTCGACATGGCGGCCCCCG-3' and reverse, 5' AGCGGATCCTTGATAGTCTGGTAGCCTGCGT-3'), digestion Sall and BamHI and ligation in the pmTurquoise2-N1 plasmid, cut with the same enzymes.

Detailed sequence information can be accessed at www.addgene.org or requested from the corresponding author.

\section{Cell culture \& Sample Preparation}

HeLa cells (American Tissue Culture Collection: Manassas, VA, USA) were cultured using Dulbecco's Modified Eagle Medium (DMEM) supplied with Glutamax, 10\% FBS (without antibiotics). Cell culture, transfection and live cell microscopy conditions were previously described (REF). Transfection was 
performed with lipofectamine 2000, using 1-2 $\mu$ l of lipofectamine, $50 \mu$ of OptiMEM and $\sim 500 \mathrm{ng}$ of plasmid DNA per $24 \mathrm{~mm}$ coverslip. Alternatively, we used PEI, with $4.5 \mu \mathrm{l}$ of PEI, $200 \mu \mathrm{l}$ of OptiMEM and $500 \mathrm{ng}$ of plasmid DNA per $24 \mathrm{~mm}$ coverslip.

\section{Microscopy}

Images were acquired on a Zeiss LSM META confocal microscope with settings as follows. For mTurquoise 2 we used $458 \mathrm{~nm}$ excitation and a BP480-520 nm emission filter. For mNeonGreen we used $488 \mathrm{~nm}$ excitation and a BP500-530 $\mathrm{nm}$ emission filter. For mScarletl we used $543 \mathrm{~nm}$ excitation and a LP560 nm. Alternatively we use a Nikon A1 confocal microscope with settings as follows. For mTurquoise 2 we used $458 \mathrm{~nm}$ excitation and a 482/35 nm emission filter. For mScarlet-I we used $561 \mathrm{~nm}$ excitation and a BP 595/50 nm emission filter. All images were acquired with the pinhole set to 1 airy unit.

\section{Availability of materials}

Plasmid DNA encoding the improved markers described in this study will be distributed by Addgene if possible, together with full plasmid sequences and additional information at https://www.addgene.org/Dorus_Gadella/

\section{Acknowledgments}

The cDNA encoding mCherry-LaminB (Bas van Steensel), EB3-EGFP (Niels Galjart) EGFP-LAMP1 (Eric Reits) were kind gifts from colleagues.

\section{Competing interests}

The authors declare no competing or financial interests.

\section{Author contributions}

All authors participated in this study, either by generating plasmids with markers, fluorescence microscopy or writing (or a combination thereof). 


\section{References}

Belin, B.J., Goins, L.M., and Mullins, R.D. (2014). Comparative analysis of tools for live cell imaging of actin network architecture. Bioarchitecture 4, 189202.

Bindels, D.S., Haarbosch, L., van Weeren, L., Postma, M., Wiese, K.E., Mastop, M., Aumonier, S., Gotthard, G., Royant, A., Hink, M.A., et al. (2017). mScarlet: a bright monomeric red fluorescent protein for cellular imaging. Nat. Methods 14, 53-56.

Burkel, B.M., von Dassow, G., and Bement, W.M. (2007). Versatile fluorescent probes for actin filaments based on the actin-binding domain of utrophin. Cell Motil. Cytoskeleton 64, 822-832.

Ganguly, A., Tang, Y., Wang, L., Ladt, K., Loi, J., Dargent, B., Leterrier, C., and Roy, S. (2015). A dynamic formin-dependent deep F-actin network in axons. J. Cell Biol. 210, 401 LP-417.

Goedhart, J., von Stetten, D., Noirclerc-Savoye, M., Lelimousin, M., Joosen, L., Hink, M.A., van Weeren, L., Gadella, T.W.J., and Royant, A. (2012). Structure-guided evolution of cyan fluorescent proteins towards a quantum yield of $93 \%$. Nat. Commun. 3, 751.

Johnson, H.W., and Schell, M.J. (2009). Neuronal IP3 3-Kinase is an F-actinbundling Protein: Role in Dendritic Targeting and Regulation of Spine Morphology. Mol. Biol. Cell 20, 5166-5180.

Joosen, L., Hink, M.A., Gadella, T.W.J., and Goedhart, J. (2014). Effect of fixation procedures on the fluorescence lifetimes of Aequorea victoria derived fluorescent proteins. J. Microsc. 256, 166-176.

Komatsu, T., Kukelyansky, I., McCaffery, J.M., Ueno, T., Varela, L.C., and Inoue, T. (2010). Organelle-specific, rapid induction of molecular activities and membrane tethering. Nat Meth 7, 206-208.

Prasher, D.C., Eckenrode, V.K., Ward, W.W., Prendergast, F.G., and Cormier, M.J. (1992). Primary structure of the Aequorea victoria green-fluorescent protein. Gene 111, 229-233.

Riedl, J., Crevenna, A.H., Kessenbrock, K., Yu, J.H., Neukirchen, D., Bista, M., Bradke, F., Jenne, D., Holak, T.A., Werb, Z., et al. (2008). Lifeact: a versatile marker to visualize F-actin. Nat Methods 5, 605-607.

Rizzuto, R., Brini, M., Giorgi, F. De, Rossi, R., Heim, R., Tsien, R.Y., and Pozzan, T. (1996). Double labelling of subcellular structures with organelletargeted GFP mutants in vivo. Curr. Biol. 6, 183-188.

Shaner, N.C., Steinbach, P.A., and Tsien, R.Y. (2005). A guide to choosing fluorescent proteins. Nat Methods 2, 905-909. 
Shaner, N.C., Lambert, G.G., Chammas, A., Ni, Y., Cranfill, P.J., Baird, M.A., Sell, B.R., Allen, J.R., Day, R.N., Israelsson, M., et al. (2013). A bright monomeric green fluorescent protein derived from Branchiostoma lanceolatum. Nat. Methods 10, 407-409.

Shcherbakova, D.M., Hink, M.A., Joosen, L., Gadella, T.W., and Verkhusha, V. V (2012). An orange fluorescent protein with a large Stokes shift for singleexcitation multicolor FCCS and FRET imaging. J Am Chem Soc 134, 79137923.

Shcherbakova, D.M., Baloban, M., Emelyanov, A. V, Brenowitz, M., Guo, P., and Verkhusha, V. V (2016). Bright monomeric near-infrared fluorescent proteins as tags and biosensors for multiscale imaging. Nat. Commun. 7, 12405.

Snaith, H.A., Anders, A., Samejima, I., and Sawin, K.E. (2010). New and Old Reagents for Fluorescent Protein Tagging of Microtubules in Fission Yeast. Methods Cell Biol. 97, 147-172.

Spracklen, A.J., Fagan, T.N., Lovander, K.E., and Tootle, T.L. (2014). The pros and cons of common actin labeling tools for visualizing actin dynamics during Drosophila oogenesis. Dev. Biol. 393, 209-226.

Stepanova, T., Slemmer, J., Hoogenraad, C.C., Lansbergen, G., Dortland, B., De Zeeuw, C.I., Grosveld, F., van Cappellen, G., Akhmanova, A., and Galjart, N. (2003). Visualization of Microtubule Growth in Cultured Neurons via the Use of EB3-GFP (End-Binding Protein 3-Green Fluorescent Protein). J. Neurosci. 23, 2655 LP-2664.

van Unen, J., Reinhard, N., Yin, T., Wu, Y., Postma, M., Gadella, T., and Goedhart, J. (2015). Plasma membrane restricted RhoGEF activity is sufficient for RhoA-mediated actin polymerization. Sci. Rep. 5, 14693. van Unen, J., Yin, T., Wu, Y.I., Mastop, M., Gadella, T.W.J., and Goedhart, J. (2016). Kinetics of recruitment and allosteric activation of ARHGEF25 isoforms by the heterotrimeric G-protein Gaq. Sci. Rep. 6, 36825. 


\section{Supplemental information}

Amino acid sequences of the targeting peptides or protein domains

1xmts is residue 1-29 of HsCOX8A:

MSVLTPLLLRGLTGSARRLPVPRAKIHSL

\section{4xmts:}

MSVLTPLLLRGLTGSARRLPVPRAKIHSLGDPMSVLTPLLLRGLTGSARR LPVPRAKIHSLGKLATMSVLTPLLLRGLTGSARRLPVPRAKIHSLGDPMS VLTPLLLRGLTGSARRLPVPRAKIHSLG.

1xnls is residue $126-132$ of the SV40 large T antigen:

PKKKRKV

3xnls is:

MGLRSRADPKKKRKVDPKKKRKVDPKKKRKV

Lck is residue 1-10 of MmLck:

MGCVCSSNPE

p63(1-29) from Hsp63RhoGEF is:

MRGGHKGGRCACPRVIRKVLAKCGCCFAR

GalT has residue 1-61 of HsB4GALT:

MRLREPLLSGSAAMPGASLQRACRLLVAVCALHLGVTLVYYLAGRDLSRL PQLVGVSTPLQ

Giantin is residue 3131-3259 of HsGiantin:

EPQQSFSEAQQQLCNTRQEVNELRKLLEEERDQRVAAENALSVAEEQIRR LEHSEWDSSRTPIIGSCGTQEQALLIDLTSNSCRRTRSGVGWKRVLRSLC HSRTRVPLLAAIYFLMIHVLLILCFTGHL

IPTKA also known as Ftractin is residue 9-40 of Rat IPTKA: MGMARPRGAGPCSPGLERAPRRSVGELRLLFEA

UtrCH is residue 1-261 from HsUtrophin

Lifeact is residue 1-17 from Abp140 (Saccharomyces cerevisiae): MGVADLIKKFESISKEE 